\title{
Comparing Hedge Funds: Highest Return Strategy
}

\author{
Greyson Meek, \& Vuk Janus \\ Warrington College of Business
}

Faculty Mentor: Anne Donnelly, Center for Undergraduate Research

\begin{abstract}
Since 1997, the hedge fund industry has grown at a compounded annual growth rate of $16.07 \%$, resulting in a 26-fold increase from its original value to its present value of $\$ 3.1$ trillion Assets Under Management. This study researched the varying investment strategies used by hedge funds to determine the strategy that provides the highest returns for its investors. From the previous literature, the study identified Long/Short Equity, Global Macro, Arbitrage, Event Driven, and Cross-Asset Multi-Strategy as viable and relevant investment approaches. Using hedge fund index data from Bloomberg, Hedge Fund Research, Eureka Hedge, Barclay's, and Credit Suisse, returns for each respective strategy were collected and compared against the Bloomberg Global Hedge Fund (BHEDGE) Index and the S\&P 500 Index. Alpha adjusted returns for each strategy were later calculated and plotted against the average weighted returns of each individual strategy. The results of this study show that the L/S Equity strategy provided the highest returns for its investors. Specifically, only the L/S Equity strategy outperformed the BHEDGE Index by a narrow margin, while all other strategies provided negative alpha figures. All hedge fund strategies outperformed the overall equity market on a year-to-date basis, however, provided negative alpha returns when compared to the S\&P 500 1-Year market gains. This deficit between hedge funds and the overall equity markets can be attributed to the unusual circumstances created within the financial markets as a result of low fixed income interest rates, economic demand stimulus, and overall equity market volatility.

Keywords: Hedge Funds, Hedge Fund Strategies, Rate of Return, Alpha, S\&P500, Equities, Arbitrage, Macro, Event-Driven, Multi-Strategy
\end{abstract}

\section{Introduction}

Through the progression of the research, the focus of the paper has been directed towards the topic of hedge funds and strived to answer the question: which hedge fund investment strategy within the United States offers the highest average annual returns for investors based on the 5year historical average? The result of this study will aim to address the gap within the current literature that fails to provide a substantial quantitative method to assess rate of return for hedge funds based on the specific investment approach they utilize. 
The importance of hedge funds in the modern financial services sector is highlighted by the size of the industry, which has grown exponentially within the past 25 years. The value of the assets under management (AUM) of the hedge fund industry in 1997 was just under $\$ 120$ billion, while the value of the AUM of the industry rose to over $\$ 3.1$ trillion in 2019, representing more than a 26-fold increase (Norrestad, 2020d). This statistic becomes even more reflective of the importance of hedge funds within the financial sector when compared to the size of the largest global economies. The current value of the AUM within the hedge fund industry surpasses the GDP of India, world's 5th largest economy (World Bank Data, 2021). This study will group hedge funds according to their investment strategies. Thus, this paper identified 5 main hedge fund types according to the insights of Neil O'Hara, a finance professional with more than 28 years of experience within the financial services sector and a prolific writer of articles for financial industry professionals. The hedge funds in this study were grouped into the following 5 categories: Long/Short (L/S) Equity, Global Macro, Event Driven, Arbitrage, (Fixed Income, Merger, Convertible) and Cross Asset Multiple (O’Hara, 2021). The L/S Equity strategy invests into publicly traded equities and uses both a long and short approach to obtain returns. The Global Macro strategy invests into global macroeconomic assets like currencies and cryptocurrencies, while the Event Driven strategy aims to create returns by investing around large-scale financial events such as mergers and takeovers. Arbitrage, for the case of simplicity, is used as an umbrella term than encompasses all different strategies that create returns by taking advantage of pricing inefficiencies within the free market. Lastly, Cross Asset Multiple strategy employs a combination of different investment strategies to optimize the rate of return for investors.

A commonality that arises is the inconsistent findings to produce a method to evaluate varying techniques to invest. Each author conveys the lack of a singular, definitive approach to analyze and assess the performances of hedge funds across any industry. Financial experts also conflict on the fundamental reason for why an analysis and evaluation of investment strategies remains a gap in knowledge in the finance sector. Giuzio et al. explains this disparity, for financial literature majorly attributes the returns of hedge funds to alternative betas while professionals hold managerial skills as the main factor responsible for higher profits (Giuzio, 2018). O'Doherty, Savin, and Tiwari highlight the effect of an extreme variance in the investment strategies that hedge funds utilize as well as the little transparency and restrictions 
enforced onto the finance service institutions (O'Doherty, 2016). Similarly, Camarero Aguilera and López-Pascual hold the diverse nature of investment techniques responsible for the innate difficulty to assess and evaluate each strategy (Camarero, 2013).

Each study demonstrates a different methodology that gauges strategies and addresses the limitations with past evaluation techniques. Bernard et al. expands upon former concepts researched and published, Dybvig's cost-efficiency (1998) and Amin and Kat's efficiency tests (2003), to include specific benchmarks and better financially examine the institutions. The resulting inclusion of benchmarks proved that the performance of an investment strategy was not due to the management's skills or expertise (Bernard, 2019). Li, Xu, and Zhang investigate the ability of Farnsworth, Ferson, Jackson, and Todd's (FFJT) stochastic discount factor (SDF) framework (2002) with the incorporation of models with option and time-averaged risk elements and model estimation combined with option returns. The development of the established framework resolved the underlying biases of simulated models and better evaluated the influence of managers of 2,315 long/short equity hedge funds. The computed data proved that the average long/short equity fund fails to exceed the market except for a small percentage of successful institutions (Li, 2016). Dr. Camarero and his peers reveal the faults of using a traditional mean variance method and the potential of combining the strategies' historical returns with options pay off and low intensive investing as a procedure to validate the hedge fund's structured fee. The researchers modeled various investment strategies (arbitrage, market neutral equity, and long/short equity), and as a result, the simulations outperformed the actual returns, verified the successfulness of low intensive trading, and refuted the structured fee charged by funds (Camarero, 2013). Michael O'Doherty and his associates pioneered a new approach to assessing the investment strategy of hedge funds. The researchers constructed a model pooling technique to create a strategy-specific benchmark by collecting from a diverse attribution model and abandoning the Fung and Hsieh model, stepwise regression approach, and style adjusted method. The study used hedge funds from 1994 to 2001 with different investment strategies (global macro, fixed income and convertible arbitrage, event drive, equity market neutral, and long/short equity) for comparison and confirmed a statistically significant evaluation to predict risk exposure and future monthly returns (O’Doherty, 2016).

Giuzio et al. evaluates the systematic risk exposure of 28 different HFRI hedge fund indices, categorized into groups by the strategy they employ, towards different sets of liquid asset classes. 
The analysis utilizes log-penalties to eliminate less relevant factors, thus removing a significant amount of complexity and statistical uncertainty from the method and allowing the index logclones to track fund returns more closely. The study categorized the hedge fund indices according to the following strategies: Event Driven, Equity Hedge, Emergency Markets, Funds of Funds, Macro, and Relative Value, and evaluated their alternative beta exposures to numerous factors relating to liquid asset classes. Beta values measure the inherent risk exposure of an investment by measuring its implied volatility against a common benchmark, in most cases the S\&P500 Index. The results are useful to quantify different risk exposures in a statistical analysis. The analysis confirmed an older study's hypothesis that hedge fund strategies' performances are primarily driven by their alternative betas, thus proving that risk exposure plays a significant role in a fund's returns. The study was even able to quantify alternative betas for the previously identified hedge fund strategies against 4 main liquid asset classes identified through the logpenalty as equity, bond, commodity, and currency. The results of the analysis confirm that macro strategies have the largest alternative beta exposure towards currencies, while event-driven strategies have the largest alternative beta exposure towards bonds. On the other hand, equitybased strategies maintain the largest equity exposure as expected (Giuzio, 2018).

The most current statistics which cover the topics of hedge fund returns, risks, performance, and asset flows range from 2015 to 2019. The current collected data suggests that in 2017 , the L/S equity strategy had the highest annual returns of $13.41 \%$, while the global macro strategy had the lowest annual returns of $2.14 \%$. Market neutral equity fell second with annual returns of $8.45 \%$, and event driven, and arbitrage followed closely at $6.3 \%$ and $5.77 \%$ respectively (Norrestad, 2020a). The data on global performance of individual hedge funds identifies Odey European Inc. with 53\% returns, Gresham Quant Acar Fund with 28.58\% returns, and Millburn Commodity program with $23.39 \%$ returns as the 3 highest performing funds of 2018 (Norrestad, 2020b). Odey European Inc. employs a L/S equity strategy, and Gresham Quant Acar and Millburn Commodity employ alternative commodity strategies that fall outside the scope of this study. It is evident that L/S equity has the largest performance spread between top and bottom decile funds, equaling 38.9\%. Global macro and event driven strategies follow closely by at $33.2 \%$ and $31.2 \%$ respectively, and equity market neutral falls at a more modest $25.3 \%$ (Norrestad, 2020c). The most recent data on asset flows within hedge funds shows that in 2019 all of the different investment strategies sustained significant asset outflows, with the combined 
industry outflows totaling nearly $\$ 100$ billion in value. Event driven strategy sustained the largest asset outflows of more than $\$ 31$ billion, the equity strategies totaled outflows around $\$ 18$ billion, and macro strategies earned outflows of just over $\$ 9.5$ billion (Norrestad, 2020e). The combined information from this data that will be utilized in the study's statistical analysis to quantify hedge fund returns for the different strategies within the scope of the paper.

Through identification of specific average rate of return on investment and index-adjusted alpha for each hedge fund strategy, this study can educate current and potential investors alike as to which hedge fund is best suited to their personal and financial goals. The result of the increased education about hedge funds could promote a sense of security and confidence amongst the public, thus increasing investment participation within the hedge fund industry. This effect would serve to support and bolster growth across the hedge fund industry and provide a platform for an increase in investors and assets under management within financial service institutions. In order to obtain a quantifiable average rate of return and an index-adjusted alpha for each hedge fund strategy, this study will collect 5-year historical return data for individual hedge funds and appropriate it for a comparison using a statistical analysis.

\section{Research Methods}

This study utilized a comparative statistical analysis using historical 1-year (1Y) and YearTo-Date (YTD) returns of hedge funds collected from hedge fund indices to quantify the average investment returns and alpha adjusted returns for each of the 5 hedge fund strategies identified: L/S Equity, Global Macro, Event Driven, Arbitrage, and Cross-Asset Multi-Strategy. The analysis selected all the individual hedge funds from the holdings of the following index sources: Bloomberg Hedge Fund (BBG), Eurekahedge (EFHI), Hedge Fund Research (HFR), Barclay's Hedge Fund (BHFI), and Credit Suisse Hedge Fund (CHFI). Subsequently, the 1Y and YTD historical returns were located and quantified for each of the 5 strategies. An average of each strategy's returns was calculated from all 5 sources, and this average figure was later used for comparison as it offers a larger diversification of results. As a benchmark, the 1Y and YTD historical performance of the S\&P 500 Index (SPX) were directly compared with the results in order to calculate the respective alpha adjusted returns of each fund strategy. Further, the average 1Y and YTD historical returns of a second benchmark, the Bloomberg Global Hedge Fund Index (BHEDGE), were used for a second alpha calculation. Alpha adjusted returns were calculated by 
finding the difference between the average returns of each hedge fund strategy and the chosen benchmark, in this case the SPX and BHEDGE. The average returns and alpha adjusted returns for each strategy were quantified and presented graphically for a visual comparison. Lastly, the return data was compared between the fund strategies in order to identify the optimal fund strategy for different investor types based on their personal and financial goals.

\section{Results}

Table 1. Return Figures \& Alphas for Each Index and Strategy

\begin{tabular}{|c|c|c|c|c|c|c|c|}
\hline Strategy & Index & $\begin{array}{c}\text { YTD } \\
\text { Return }\end{array}$ & $\begin{array}{c}1 Y \\
\text { Return }\end{array}$ & $\begin{array}{c}\text { BBG Alpha: } \\
\text { YTD }\end{array}$ & $\begin{array}{c}\text { BBG Alpha: } \\
1 Y\end{array}$ & $\begin{array}{c}\text { S\&P Alpha: } \\
\text { YTD }\end{array}$ & $\begin{array}{c}\text { S\&P Alpha: } \\
1 Y\end{array}$ \\
\hline \multicolumn{8}{|c|}{ Equity L/S } \\
\hline & BBG L/S & $4.93 \%$ & $23.38 \%$ & $1.04 \%$ & $6.54 \%$ & $3.20 \%$ & $-5.18 \%$ \\
\hline & EHFI L/S & $5.29 \%$ & $17.87 \%$ & $1.40 \%$ & $1.03 \%$ & $3.56 \%$ & $-10.69 \%$ \\
\hline & HFR L/S & $6.35 \%$ & $30.79 \%$ & $2.46 \%$ & $13.95 \%$ & $4.62 \%$ & $2.23 \%$ \\
\hline & BHFI L/S & $5.57 \%$ & $9.27 \%$ & $1.68 \%$ & $-7.57 \%$ & $3.84 \%$ & $-19.29 \%$ \\
\hline & CHFI L/S & $-2.80 \%$ & $5.67 \%$ & $-6.69 \%$ & $-11.17 \%$ & $-4.53 \%$ & $-22.89 \%$ \\
\hline \multicolumn{8}{|l|}{ Macro } \\
\hline & BBG GM & $3.68 \%$ & $11.95 \%$ & $-0.21 \%$ & $-4.89 \%$ & $1.95 \%$ & $-16.61 \%$ \\
\hline & EHFI GM & $2.05 \%$ & $10.94 \%$ & $-1.84 \%$ & $-5.90 \%$ & $0.32 \%$ & $-17.62 \%$ \\
\hline & HFR GM & $3.81 \%$ & $10.64 \%$ & $-0.08 \%$ & $-6.20 \%$ & $2.08 \%$ & $-17.92 \%$ \\
\hline & BHFI GM & $2.44 \%$ & $10.06 \%$ & $-1.45 \%$ & $-6.78 \%$ & $0.71 \%$ & $-18.50 \%$ \\
\hline & CHFI GM & $0.32 \%$ & $6.87 \%$ & $-3.57 \%$ & $-9.97 \%$ & $-1.41 \%$ & $-21.69 \%$ \\
\hline \multicolumn{8}{|l|}{ Arbitrage } \\
\hline & BBG ARB & $2.53 \%$ & $13.81 \%$ & $-1.36 \%$ & $-3.03 \%$ & $0.80 \%$ & $-14.76 \%$ \\
\hline & EHFI ARB & $1.22 \%$ & $10.59 \%$ & $-2.67 \%$ & $-6.25 \%$ & $-0.51 \%$ & $-17.97 \%$ \\
\hline & HFR ARB & $4.22 \%$ & $13.48 \%$ & $0.33 \%$ & $-3.37 \%$ & $2.49 \%$ & $-15.09 \%$ \\
\hline & BHFI ARB & $4.71 \%$ & $11.72 \%$ & $0.82 \%$ & $-5.12 \%$ & $2.98 \%$ & $-16.84 \%$ \\
\hline & CHFI ARB & $1.34 \%$ & $7.98 \%$ & $-2.55 \%$ & $-8.86 \%$ & $-0.39 \%$ & $-20.58 \%$ \\
\hline \multicolumn{8}{|c|}{ Event Driven } \\
\hline & BBG ED & $6.48 \%$ & $18.26 \%$ & $2.59 \%$ & $1.42 \%$ & $4.75 \%$ & $-10.30 \%$ \\
\hline & EHFI ED & $4.46 \%$ & $7.85 \%$ & $0.57 \%$ & $-8.99 \%$ & $2.73 \%$ & $-20.71 \%$ \\
\hline & HFR ED & $5.94 \%$ & $19.21 \%$ & $2.05 \%$ & $2.37 \%$ & $4.21 \%$ & $-9.35 \%$ \\
\hline & BHFI ED & $4.84 \%$ & $11.12 \%$ & $0.95 \%$ & $-5.72 \%$ & $3.11 \%$ & $-17.44 \%$ \\
\hline & CHFI ED & $1.40 \%$ & $8.34 \%$ & $-2.49 \%$ & $-8.50 \%$ & $-0.33 \%$ & $-20.22 \%$ \\
\hline \multicolumn{8}{|l|}{ Multi } \\
\hline & BBG MUL & $3.43 \%$ & $11.29 \%$ & $-0.46 \%$ & $-5.56 \%$ & $1.70 \%$ & $-17.28 \%$ \\
\hline & EHFI MUL & $1.86 \%$ & $7.83 \%$ & $-2.03 \%$ & $-9.01 \%$ & $0.13 \%$ & $-20.73 \%$ \\
\hline & HFR MUL & $4.23 \%$ & $21.19 \%$ & $0.34 \%$ & $4.35 \%$ & $2.50 \%$ & $-7.37 \%$ \\
\hline & BHFI MUL & $3.10 \%$ & $4.23 \%$ & $-0.79 \%$ & $-12.61 \%$ & $1.37 \%$ & $-24.33 \%$ \\
\hline & CHFI MUL & $-0.49 \%$ & $4.00 \%$ & $-4.38 \%$ & $-12.84 \%$ & $-2.22 \%$ & $-24.56 \%$ \\
\hline
\end{tabular}


Table 2. Average Return Figures \& Alphas for Each Strategy

\begin{tabular}{|c|c|c|c|c|c|c|}
\hline Strategy & $\begin{array}{l}\text { Avg YTD } \\
\text { Returns }\end{array}$ & $\begin{array}{l}\text { Avg 1Y } \\
\text { Returns }\end{array}$ & $\begin{array}{c}\text { Avg BBG } \\
\text { Alpha: YTD }\end{array}$ & $\begin{array}{l}\text { Avg BBG } \\
\text { Alpha: } 1 Y\end{array}$ & $\begin{array}{c}\text { Avg S\&P } \\
\text { Alpha: YTD }\end{array}$ & $\begin{array}{c}\text { Avg S\&P } \\
\text { Alpha: 1Y }\end{array}$ \\
\hline Equity L/S & $3.87 \%$ & $17.40 \%$ & $-0.02 \%$ & $0.56 \%$ & $2.14 \%$ & $-11.17 \%$ \\
\hline Macro & $2.46 \%$ & $10.09 \%$ & $-1.43 \%$ & $-6.75 \%$ & $0.73 \%$ & $-18.47 \%$ \\
\hline Arbitrage & $2.80 \%$ & $11.52 \%$ & $-1.09 \%$ & $-5.33 \%$ & $1.07 \%$ & $-17.05 \%$ \\
\hline Event Driven & $4.62 \%$ & $12.96 \%$ & $0.73 \%$ & $-3.88 \%$ & $2.89 \%$ & $-15.61 \%$ \\
\hline Multi & $2.43 \%$ & $9.71 \%$ & $-1.47 \%$ & $-7.13 \%$ & $0.70 \%$ & $-18.86 \%$ \\
\hline
\end{tabular}

As Table 2 depicts, all of the 5 strategies had positive YTD and 1Y returns. Out of all the strategies, Event Driven had the highest YTD return figure at $4.62 \%$, while the L/S Equity strategy had the highest $1 Y$ return figure at $17.40 \%$. Subsequently, the Event Driven strategy was the only one that outperformed the Bloomberg Global Hedge Fund Index in the YTD timeframe with an alpha-adjusted return of $0.73 \%$. On the other hand, the L/S Equity strategy was the only one that outperformed the Bloomberg Global Hedge Fund Index in the 1Y timeframe with an alpha-adjusted return of $0.56 \%$. Looking at the S\&P500 alpha-adjusted returns shows that all of the 5 strategies outperformed the overall equity markets in the YTD timeframe, evident by the positive alpha figures. Despite this, all of the 5 strategies were outperformed by the equity markets in the 1Y timeframe, as evident by the negative alpha figures. The Cross-Asset MultiStrategy hedge funds were outperformed the most by the S\&P500 index, averaging an alpha figure of $-18.86 \%$.

\section{Conclusion}

Hedge funds, as an alternative asset class, typically tend to produce larger return figures than equity markets relative to their risk exposure. Hedge funds are seriously managed businesses which operate with the aim of growing their clients' portfolios over time while hedging traditional equity market risks, thus requiring very skilled and experienced portfolio managers and directors. They are often able to outperform the market due to their alpha-driven return focus, whereas the equity markets can only provide beta-driven returns correlated with the underlying risk. Despite this, last year the S\&P500 Index directly beat out all the individual strategies this study identified, evident by the negative $1 \mathrm{Y}$ alpha figure. However, when looking at the short-term returns quantified by the YTD returns, hedge funds clearly beat out the equity 
markets in every strategy category. This study believes that there are several reasons behind these results, however, all of them tend to relate to the unusual state of financial markets during the COVID-19 pandemic. Firstly, the low interest rate policy set by the Federal Reserve in light of the anticipated recession helped lower the yields within the fixed-income markets. These historically low yields drove many fixed-income investors to transfer their assets into the equity markets, thus raising equity prices through increased demand. Stimulus packs by the Federal Government also helped raise equity prices after they first dipped by increasing the overall economic demand in the product markets, thus raising company earnings for a short period of time. Lastly, the increased volatility seen within the equity markets last year resulted in increased S\&P500 return figures, yet, these returns carried a significant amount of underlying risk exposure. Because hedge funds prefer to maximize risk-adjusted returns by hedging market risks, they were not able to fully capitalize on all of the volatility within the equity markets, despite achieving great returns. These are the factors believed to have caused the S\&P500 to outperform hedge funds last year, although more research should be conducted specifically aiming to determine and quantify the economic impacts of the COVID-19 pandemic and the subsequent response by both the White House and Federal Reserve on the financial markets.

\section{Acknowledgements}

Undoubtedly, there are individuals who aided us from the very start of this study and guided us throughout the entire development of the research. The first of these people is our outstanding TA, Lorca Stainton. Lorca served a critical role of leading us through the numerous steps that are inherit when conducting research as well as editing our paper to a professional standard. Further, Dr. Anne Donnelly, the Director of the Center for Undergraduate Research (CUR) and professor of Explorations in Business Research, acted as an influential leader and effective teacher. The opportunity for students to conduct personalized research in a class setting and gain invaluable experience would not be possible without her amazing contributions to the University of Florida. Finally, Professor Michelle Leonard, a professor of Explorations in Business Research and CUR librarian, was a significant contributor of our research. She administered a substantial revision of our final research paper that perfected the minute details for the format, organization, and overall edits. In the end, the collaboration from our TA and both professors eased the entire research process, and the following result would not be possible without their help. 


\section{References}

Bernard, C., Vanduffel, S., \& Ye, J. (2019). A new efficiency test for ranking investments: Application to hedge fund performance. Economics Letters, 181, 203-207.

https://doi.org/10.1016/j.econlet.2019.05.023

Camarero Aguilera, S., \& López-Pascual, J. (2013). Analysing hedge fund strategies through the use of an option based approach. Spanish Journal of Finance and Accounting, 42(158), 167-186.

https://doi.org/10.1080/02102412.2013.10779744

GDP (current US\$) - India. World Bank Data. (2021).

https://data.worldbank.org/indicator/NY.GDP.MKTP.CD?locations=IN.

Giuzio, M., Eichhorn-Schott, K., Paterlini, S., \& Weber, V. (2018). Tracking hedge funds returns using sparse clones. Annals of Operations Research, 266(1/2), 349-371.

https://doi.org/10.1007/s10479-016-2371-5

Li, H., Xu, Y., \& Zhang, X. (2016). Hedge Fund Performance Evaluation under the Stochastic Discount Factor Framework. Journal of Financial \& Quantitative Analysis, 51(1), 231257. https://doi.org/10.1017/S0022109016000120

Norrestad, F. (2020a). Annual returns of hedge funds in 2017, by hedge fund type. Statista. https://www.statista.com/statistics/948425/returns-on-hedge-funds-by-type/

Norrestad, F. (2020b). Leading hedge funds worldwide in 2018, by return. Statista. https://www.statista.com/statistics/948446/leading-hedge-funds-by-return/

Norrestad, F. (2020c). Performance spread of top and bottom-decile hedge fund managers worldwide in 2017, by hedge fund style. Statista. https://www.statista.com/statistics/948432/performance-topand-bottom-hedge-funds-by-style/

Norrestad, F. (2020d). Value of assets managed by hedge funds worldwide from 1997 to 2019.

Statista. https://www.statista.com/statistics/271771/assets-of-the-hedge-funds-worldwide/

Norrestad, F. (2020e). Value of hedge fund asset flows worldwide from 2015 to 2019, by hedge fund strategy. Statista. https://www.statista.com/statistics/948587/hedge-fund-asset-flows-by-strategy/

O'Doherty, M. S., Savin, N. E., \& Tiwari, A. (2016). Evaluating Hedge Funds with Pooled Benchmarks. Management Science, 62(1), 69-89. https://doi.org/10.1287/mnsc.2014.2056

O'Hara, N. (2021). The Various Strategies of Hedge Funds. Investopedia. https://www.investopedia.com/articles/investing/111313/multiple-strategies-hedge-funds.asp 